\title{
Estimating Exposure of Interior Fraser River Steelhead to Strait of Georgia and Fraser River Commercial Fisheries from 2004-2016
}

\author{
Brittany T. Jenewein, Mike A. Hawkshaw, and Marla R. Maxwell \\ Fisheries and Oceans Canada, 100 Annacis Parkway, Delta, British Columbia, Canada, V3M 6A2
}

Keywords: steelhead, exposure model, Fraser River, Bayesian hierarchical model, fisheries management

An objective of the Southern British Columbia Salmon Integrated Fisheries Management Plan (IFMP) is to minimize the impact of Canadian fisheries on Interior Fraser River (IFR) Steelhead to increase their spawner abundance. For Fraser river commercial gillnet fisheries, the current strategy is to protect $80 \%$ of the IFR Steelhead run with a high degree of certainty (DFO 2017a). The IFR Steelhead run is composed of three populations: Thompson, Chilcotin, and West Fraser.

Steelhead are not targeted by Canadian commercial fisheries (CCFs) but occur as bycatch in various salmontargeted fisheries including First Nations Economic Opportunity (EO) fisheries targeting late-run Fraser River Sockeye, Fraser River Pink, and southern B.C./Washington Chum salmon. The main management tool used to protect IFR Steelhead from Fraser River CCFs is to allow only a small window for Chum fisheries, such that $80 \%$ of the steelhead run can migrate from the mouth to the spawning grounds without being intercepted. Management actions currently only affect Chum-directed fisheries because they occur at the same time IFR Steelhead are migrating through the Fraser River. DFO is reviewing this strategy for 2018 and considering management actions in marine fisheries and Fraser River fisheries targeting Pink and Sockeye salmon to further protect IFR Steelhead. The purpose of this work was to explore the likelihood of IFR Steelhead exposure to other commercial/EO fisheries that occur along their migration route, in addition to the Fraser River Chum-directed fisheries.

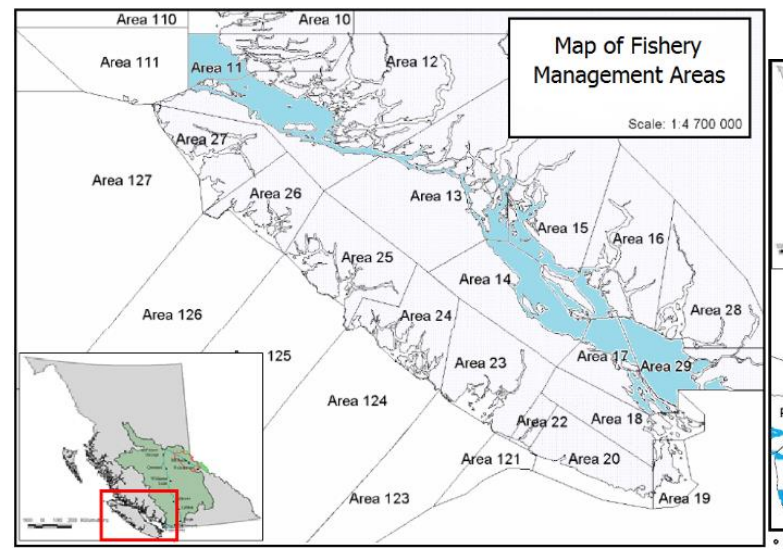

Fig. 1a. Map of Fisheries and Oceans Canada South Coast fishery management areas (British Columbia, Canada). Waters shaded in blue were included in the IFR Steelhead exposure model. Management Area map adapted from maps by Fisheries and Oceans Canada (2017b). Inset from Rhemtulla et al. (2001).

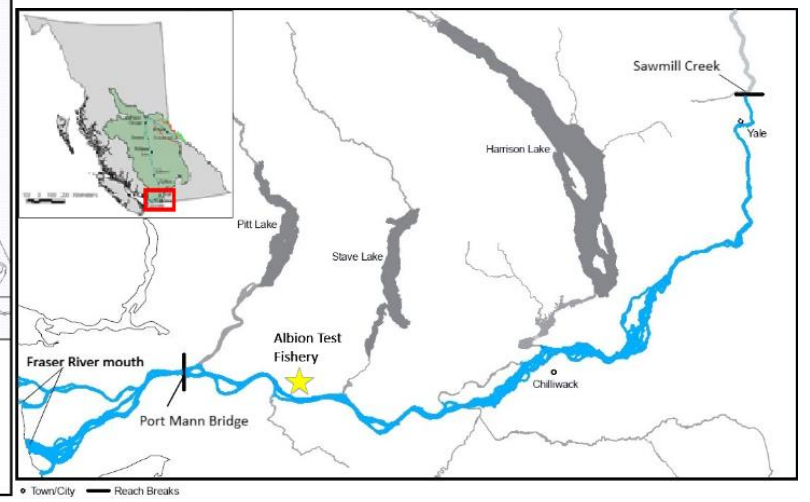

Fig. 1b. Map of lower Fraser River (British Columbia, Canada). Waters shaded in blue were included in the IFR Steelhead exposure model. Adapted from Barker (2012). Inset from Rhemtulla et al. (2001).

The current iteration of this model examines fisheries within the Strait of Georgia ("northern route") and Fraser River in British Columbia, Canada (Fig. 1). This includes five commercial fishery management areas (Areas B, D, E, G, H), and three First Nation EO fisheries from the mouth of the Fraser River to Sawmill Creek (Below Port Mann gill net (BPM GN), Above Port Mann gill net (APM GN), and Above Port Mann beach seine (APM BSn)). Each fishery was further sub-divided by target species (Sockeye, Pink, and Chum salmon), for a total of 24 fisheries. An approximate migration path through the fishing areas was measured and binned into $1 \mathrm{~km}$ increments using the measuring tool in Google Earth Pro (Google Inc. 2017). For example, management Area 12-12 (Bate Passage) begins at $\mathrm{km} 33$ and ends at $\mathrm{km} 38$. Fisheries occurring on the West and South coast of Vancouver Island ("southern route") were excluded from this first iteration of the model due to a lack of information about the 
proportion of IFR Steelhead migrating along each route (i.e., diversion rate). The starting point of migration through the CCFs $(\mathrm{km}=0)$ is the Northwest corner of Area 11-1 $\left(51^{\circ} 09^{\prime} 48.90^{\prime \prime} \mathrm{N}, 128^{\circ} 04^{\prime} 8.10^{\prime \prime} \mathrm{W}\right)$; the migration route examined extends approximately $625 \mathrm{~km}$, ending at Sawmill Creek (49³6'42.87"N, $\left.121^{\circ} 24^{\prime} 35.86^{\prime \prime} \mathrm{W}\right)$.

Published estimates of upstream Steelhead migration speed are highly variable, depending for example on the river system, freshwater or marine environment, population, and water temperature. Median and mean estimates range from $6.2 \mathrm{~km} / \mathrm{d}$ to $36.6 \mathrm{~km} / \mathrm{d}$ (e.g., Spence 1989, Burgner et al. 1992, Walker et al. 2000, Renn et al. 2001, English et al. 2006). Limited data is available on Steelhead migrating in the area examined in this analysis (Fraser River above Harrison confluence, Renn et al. 2001); therefore, for this model we employed a hypothesis about migration speed based on a similar co-migrating species for which there is tagging data, the Chum salmon. In the freshwater environment (currently approximated as the Fraser River upstream of Albion), variable migration speed was assumed to follow a normal distribution with mean $20 \mathrm{~km} \cdot \mathrm{d}^{-1}$ and SD $3 \mathrm{~km} \cdot \mathrm{d}^{-1}$ (Rosberg and Greer 1985). In the marine environment, variable migration speed is assumed to follow a normal distribution with mean $34.8 \mathrm{~km} / \mathrm{d}$ and SD $4.1 \mathrm{~km} / \mathrm{d}$ (Van Will unpublished data).

A common approach to estimating the annual 50\% date (date when half of the return is expected to have passed the reference point) and spread (or duration) of fish migration is to fit a normal distribution to catch data (Mundy 1979, Cave and Gazey 1994, Hilborn et al. 1999, Gazey and Palermo 2000). The reference point for IFR Steelhead migration is the Albion test fishery, $60.4 \mathrm{~km}$ upstream from the mouth of the Fraser River. To characterize IFR Steelhead migration, a normal distribution was fit using a Bayesian hierarchical approach to 22 years (1995-2016) of Steelhead catch data at the Albion test fishery. Gazey and Palermo (2000) details the fishery operation. The historic information from the Albion test fishery characterizes the variability of the run timing of steelhead from year to year, and the Bayesian approach reduces uncertainty in the timing estimates when annual encounters are low.

Fishery opening information for 2004 to 2016 was obtained from Fisheries and Oceans Canada's Fishery Operating System. Visual Basic for Applications (VBA) was used in Microsoft Excel to convert opening information from date and time into a cumulative hour, starting from 15 July 00:00 as hr= 0, 15 July 01:00 as hr= 1 , etc. The ending hour, $\mathrm{hr}=3335$, is equivalent to 30 November at 23:00. Opening data were transformed using VBA into a matrix of 0 's and 1 's where $0=$ closed and $1=$ open. One matrix was created for each of the 24 fisheries for each year.

The movement speed and migration hour past Albion for a simulated run of 1000 Steelhead was estimated by drawing from the normal distributions outlined above. The time when each fish would have likely been located at each $\mathrm{km}$ increment $\left(\mathrm{T}_{2}\right)$ was then calculated based on the estimated time the fish passed Albion $\left(\mathrm{T}_{\text {Albion }}\right)$ and migration speed:

$$
\begin{aligned}
& \text { Migration downstream of Albion: } T_{2}=T_{\text {Albion }}-\frac{\text { speed }}{k m_{\text {Albion }}-k m_{2}} \\
& \text { Migration upstream of Albion: } T_{2}=T_{\text {Albion }}+\frac{\text { speed }}{k m_{2}-k m_{\text {Albion }}}
\end{aligned}
$$

This information was cross-referenced with the opening matrices to determine if there was also a fishery open in the same location at the same time, which would indicate the fish was exposed to an open fishery.

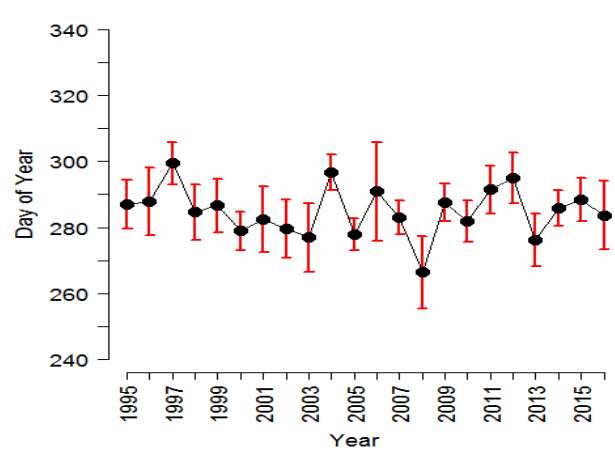

Fig. 2. Preliminary estimates of the mean (+/- 1 SD) of estimated $50 \%$ dates of the IFR Steelhead return to the Albion test fishery, 1995-2016.



Fig. 3. The mean (+/- 1 SD) of estimated variability of the IFR Steelhead return to the Albion test fishery, 1995-2016. 
The proportion of the run exposed to each fishery was estimated annually. A migration pattern for the run was drawn from the historical distribution of run spread and 50\% date estimated for each year to generate 3000 simulated patterns of IFR Steelhead migration. Each hypothesis about residence time was evaluated in terms of these 3000 simulated returns and the proportion of the run exposed to each fishery was recorded. Using these results, the cumulative exposure of each fish to fisheries each year was also estimated by counting whether each fish would have been susceptible to capture in a particular fishery (i.e., Area D Chum, Area B Sockeye, etc.) and determining the proportion of the run that may have been exposed to no fisheries, 1 fishery, 2 fisheries, etc.

Estimates of 50\% dates of return to Albion ranged from day 266 (23 September; 22 September in leap years) to day 299 (26 October; 25 October in leap years). Several years had high variability in this estimate owing to a lack of encounters in the Albion test fishery (Fig. 2). Variability around return dates did not vary much among years, ranging from 7.9 days to 10.6 days (Fig. 3), but uncertainty was high for all years.

Table 1. Preliminary estimates of mean \% exposure of Steelhead to commercial Chum-directed, Sockeye-directed, and Pinkdirected fisheries, from 2004-2016.

\begin{tabular}{lcccccc}
\hline & \multicolumn{2}{c}{ Chum-directed } & \multicolumn{2}{c}{ Pink-directed } & \multicolumn{2}{c}{ Sockeye-directed } \\
\cline { 2 - 7 } Fleet & mean \% exposure & SD & mean \% exposure & SD & mean \% exposure & SD \\
\hline Area H & 52.2 & 20.8 & 11.5 & 8.1 & 14.0 & 16.6 \\
Area D & 35.5 & 22.3 & 6.7 & 4.5 & 9.8 & 8.9 \\
BPM GN & 25.2 & 16.8 & 23.9 & 15.3 & 10.9 & 4.2 \\
Area B & 24.6 & 12.2 & 12.1 & 11.1 & 11.7 & 10.2 \\
APM GN & 10.2 & 5.7 & - & - & 5.8 & 3.4 \\
Area E & 7.1 & 5.1 & 6.9 & 1.9 & 4.8 & 3.4 \\
APM BSn & 5.3 & 3.4 & - & - & 2.1 & 1.5 \\
Area G & - & - & 15.5 & 4.3 & 2.1 & 0.9 \\
\hline
\end{tabular}

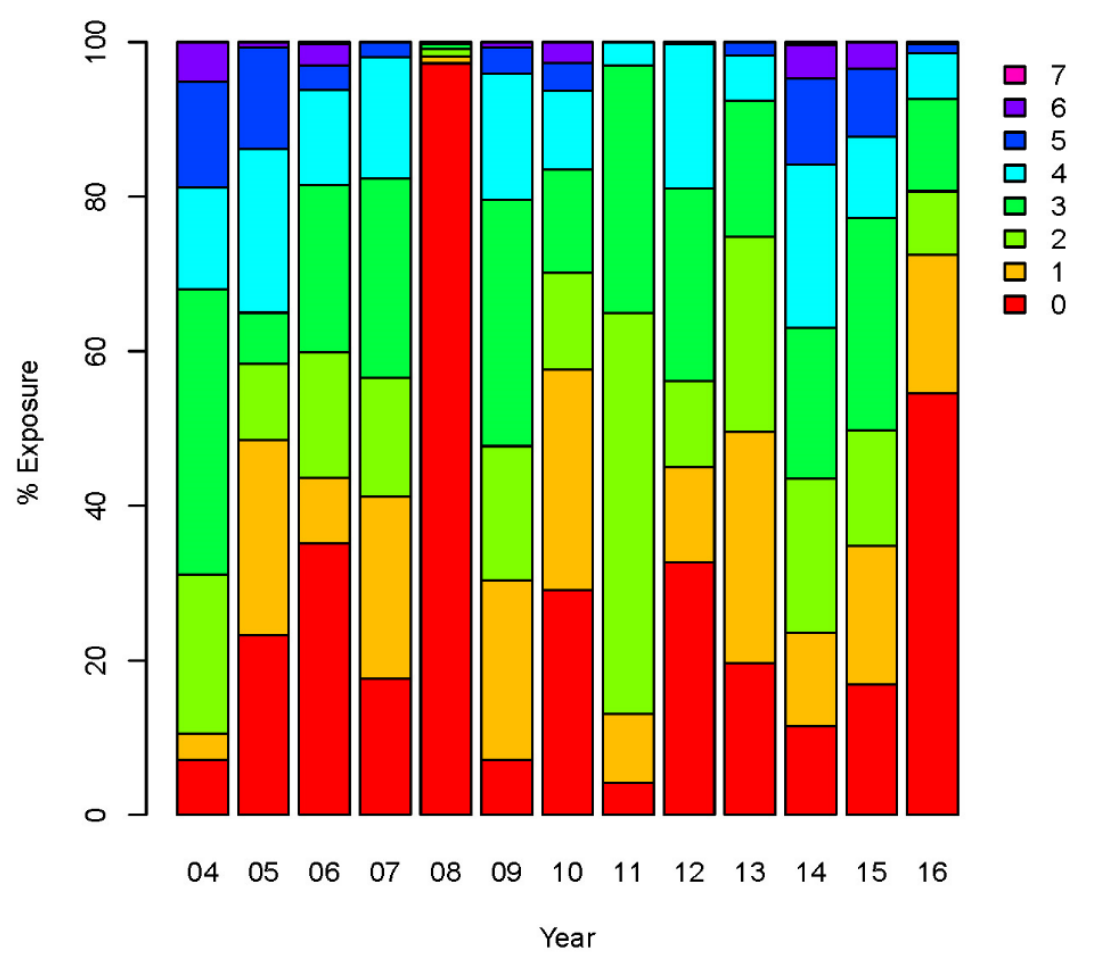

Fig. 4. Cumulative exposure of IFR Steelhead to marine and in-river commercial fisheries from 2004-2016. Legend indicates the number of fisheries. 
Preliminary reconstructions of simulated IFR Steelhead exposure to actual fisheries each year suggested that on average, some fishing fleets (e.g., Area H, Area D, BPM GN) and Chum-targeted fisheries were much more likely to expose a large proportion of the run to fishing activity than other fleets (Area G, Area E) and Sockeye- and Pink-targeted fisheries (Table 1). IFR Steelhead were not likely exposed to more than seven fisheries within a year (Fig. 4). Further, at least $60 \%$ of the run was likely exposed to three or fewer fisheries every year. This did not change much with run timing variability. This model could be adapted to forecast potential relative impacts of fishing plans using the average run timing distribution based on 22 years of historical data. It could examine exposure in both a suite of fisheries (e.g., Area B Chum, Area D Sockeye, BPM GN Chum, etc.) and within a specific fishery (e.g., alternative plans for Area B Chum). The model could also be adapted to monitor patterns of exposure over time.

This approach is not without limitations; some of the concerns with using an exposure model include: (1) annual run sizes are unknown; and (2) this model does not estimate the harvest rate for IFR Steelhead. Reliable estimates of fishery-induced mortality to estimate catchability by gear type would be needed to estimate the actual impacts. Both of the above point strongly to the need for fisher-independent information about steelhead encounters.

In summary, a preliminary analysis of historic return patterns and fishery plans suggests that some fisheries are much more likely to expose a large proportion of the IFR Steelhead run to fishing activity than others, and that extending the current in-river management objective to other commercial fishing areas will require careful consideration of other factors along with exposure (e.g., gear type, fishing effort). Additionally, migration speed assumptions may strongly influence exposure estimates, warranting further exploration with a sensitivity analysis.

\section{REFERENCES}

Barker, Stuart. 2012. Lower Fraser Area [map]. Scale Not Given. Edition 1. Delta, BC: Fisheries and Oceans Canada, Lower Fraser Area Resource Management, March 2012. Using: ArcGIS [GIS software]. Version unknown. Redlands, CA: Environmental Systems Research Institute, Inc.

Burgner, R.L., J.T. Light, L. Margolis, T. Okazaki, A. Tautz, and S. Ito. 1992. Distribution and origins of steelhead trout (Oncorhynchus mykiss) in offshore waters of the North Pacific Ocean. Int. North Pac. Fish. Comm. Bull. 51. $101 \mathrm{pp}$. (Available at http://www.npafc.org)

Cave, J.D., and Gazey, W.J. 1994. A preseason simulation model for fisheries on Fraser River sockeye salmon (Oncorhynchus nerka). Can. J. Fish. Aquat. Sci. No 51 (7): 1535-1549. doi:10.1139/f94-153.

DFO (Fisheries and Oceans Canada). 2017a. Pacific Region Integrated Fisheries Management Plan, Salmon, Southern B.C., June 1, 2017 to May 31, 2018. Fisheries Management Branch, Fisheries and Oceans Canada. Vancouver, British Columbia. 536 pp. (Available at http://waves-vagues.dfompo.gc.ca/Library/40601006.pdf)

DFO (Fisheries and Oceans Canada). 2017b. "Maps of commercial salmon licence areas in British Columbia" [maps] Scale not given. (Available at http://www.pac.dfo-mpo.gc.ca/fm-gp/maps-cartes/salmonsaumon/index-eng.html) (18 May 2018)

English, K.K., D. Robichaud, C. Sliwinski, R.F. Alexander, W.R. Koski, T.C. Nelson, and B.L. Nass. 2006. Comparison of adult steelhead migrations in the mid-Columbia hydrosystem and in large naturally flowing British Columbia rivers. Trans. Am. Fish. Soc. 135: 739-754. doi:10.1577/T05-043.1.

Gazey, W.J., and R.V. Palermo. 2000. A Preliminary Review of a New Model Based on Test Fishing Data Analysis to Measure Abundance of Returning Chum Stocks to the Fraser River. Canadian Stock Assessment Secretariat Research Document 2000/159. 30 pp. (Available at http://waves-vagues.dfompo.gc.ca/Library/252950.pdf)

Google Inc. 2017. Google Earth (Version 7.1.7.2606) [Software]. (Available at https://www.google.com/earth/download/gep/agree.html)

Hilborn, R., B.G. Bue, and S. Sharr. 1999. Estimating spawning escapements from periodic counts: a comparison of methods. Can. J. Fish. Aquat. Sci. 56:888-896. doi:10.1139/f99-013.

Mundy, P.R. 1979. A quantitative measure of migratory timing illustrated by application to the management of commercial salmon fisheries. Ph.D. thesis, Univ. Washington, Seattle. 85 pp.

Renn, J.R., R.G. Bison, J. Hagen, and T.C. Nelson. 2001. Migration characteristics and stock composition of interior Fraser steelhead as determined by radio telemetry, 1996-1999. BC Ministry of Water, Land and Air Protection, Kamloops, BC. 135 pp. 
Rosberg, G.E., and G.L. Greer. 1985. Migration rate and behaviour of adult sockeye and chum salmon through trained and untrained sections of the Lower Fraser River. Can. Tech. Rep. Fish. Aq. Sci. No. 1349. 30 pp. (Available at http://waves-vagues.dfo-mpo.gc.ca/Library/38318.pdf)

Rhemtulla, J., S.H. Marshall, and H. Hammond. 2001. "Location of the Fraser River drainage basin (green) and the Fraser Headwaters study area (outlined in red) within British Columbia." [map] In: Fraser Headwaters

Proposed Conservation Plan. Silva Forest Foundation Ecosystem-Based Conservation Planning Report. 133 pp. (Available at http://www.silvafor.org/assets/silva/PDF/Plans/Fraser.pdf)

Spence, C.R. 1989. Rates of movement and timing of migrations of steelhead trout to and within the Skeena River, 1988. Skeena Fisheries Report \#SK 62. Ministry of Environment Recreational Fisheries Branch. Smithers, British Columbia. 27 pp. (Available at http://www.env.gov.bc.ca/skeena/fish/skeena_reports/sk62.pdf)

Walker, R.V., K.W. Myers, N.D. Davis, K.Y. Aydin, K.D. Friedland, H.R. Carlson, G.W. Boehlert, S. Urawa, Y. Ueno, and G. Anma. 2000. Diurnal variation in thermal environment experienced by salmonids in the North Pacific as indicated by data storage tags. Fish. Oceanogr. 9:171-186. doi:10.1046/j.1365-

2419.2000.00131.x. 